\title{
Peningkatan Peran Aktif Mahasiswa Pada Kalkulus Integral Menggunakan Metode Pembelajaran Kooperatif Tipe Student Teams-Achievement Division
}

\author{
Sumargiyani \\ Program Studi Pendidikan Matematika FKIP, Universitas Ahmad Dahlan, Jl. Prof. Dr. Soepomo, SH \\ Janturan Yogyakarta, Indonesia
}

Korespondensi; Email: sumargiyani@yahoo.com

\begin{abstract}
Abstrak
Permasalahan dalam mengajar integral kalkulus yang membutuhkan perhatian dalam motivasi belajar bersama siswa adalah peran aktif siswa. Peran aktif siswa selama proses belajar mengajar akan berpengaruh pada hasil studinya. Adapun tujuan dari penelitian ini adalah untuk meningkatkan peran aktif siswa dengan menggunakan metode pembelajaran kooperatif tipe STAD. Subjek penelitian sebanyak 20 siswa program pendidikan PGMIPA Matematika UAD yang mengambil mata kuliah Integral Calculus semester tiga tahun ajaran 2012/2013. Siklus dilakukan sebanyak 3 kali siklus. Pengambilan data dilakukan dengan menggunakan lembar observasi, wawancara, dokumentasi, tes diagnostik dan catatan lapangan. Selanjutnya data dianalisis dengan deskriptif kualitatif. Berdasarkan hasil analisis data diketahui bahwa penggunaan metode pembelajaran kooperatif tipe STAD dapat meningkatkan peran aktif siswa pada siklus I sebesar $48,53 \%$ pada kategori cukup, siklus II meningkat sebesar $59,21 \%$ pada kategori cantik dan siklus III meningkat sebesar $71,76 \%$ pada kedua kategori.
\end{abstract}

Kata Kunci: Integral Kalkulus; STAD

\begin{abstract}
Problems in teaching integral calculus that requires attention in the motivation of learning alongside students is the active role of the student. The active role of the student during the teaching and learning process will affect on the results of his studies. As for the purpose of this research is to improve the students ' active role by using cooperative learning method type STAD. The subject of research as many as 20 students PGMIPA education courses Math UAD who take Courses Integral Calculus semester three academic year 2012/2013. The cycle is done as much as 3 times the cycle. Data collection is done using sheets of observation, interviewing, documentation, diagnostic tests and field notes. Furthermore the data analyzed by qualitative descriptive. Based on the results of data analysis revealed that the use of cooperative learning methods type STAD can enhance the active role of students in cycle I of $48.53 \%$ in category enough, cycle II increased by $59.21 \%$ in the category of pretty and cycle III increased by $71.76 \%$ in both categories.
\end{abstract}

Keywords: Integral calculus; STAD

\section{Pendahuluan}

Kalkulus integral merupakan salah satu bagian dari analisis yang merupakan salah satu cabang dari matematika. Kalkulus integral diajarkan di Pendidikan Guru Matematika dan Ilmu Pengetahuan Alam (PGMIPA) program studi Pendidikan Matematika UAD dengan bobot 3 SKS. Mata kuliah ini merupakan kelanjutan dari mata kuliah kalkulus diferensial dan sebagai mata kuliah prasyarat kalkulus lanjut.

Berdasarkan pengalaman peneliti selama mengajar kalkulus integral, dapat memperoleh suatu kesimpulan yang terkait dengan materi bahwa: (1). Sebagian besar mahasiswa lemah dalam pemahaman konsep, (2) Sebagian besar mahasiswa kurang bisa menerapkan rumus, (3) Mahasiswa kurang bisa mengintegralkan suatu fungsi dan (4). Mahasiswa sebagian besar tidak bisa menggunakan teknik 
pengintegralan. Sedangkan yang terkait dengan pembelajaran ditarik kesimpulan bahwa: (1). Sebagian mahasiswa bersifat pasip selama proses belajar mengajar (2). Mahasiswa bersifat menunggu penjelasan dosen dan (3). Mahasiswa tidak mau mengembangkan konsep yang diterima tetapi lebih senang belajar pada soal-soal latihan. Prestasi belajar mahasiswa pada mata kuliah kalkulus integral untuk nilai ujian tengah semester masih kurang memuaskan, hal ini dapat dilihat Tabel 1. berikut ini:

Tabel 1 Nilai Ujian Tengah Semester Kalkulus Integral PG MIPA Program Studi Matematika UAD TA 2012/2013.

\begin{tabular}{cl} 
Nilai & Keterangan \\
\cline { 2 - 2 } Nilai Tertinggi & 96 \\
Nilai Terendah & 20 \\
Nilai Rata-rata & 55,75 \\
Nilai C,D,E & 15 Mahasiswa \\
Nilai B & 4 Mahasiswa \\
Nilai A & 1 Mahasiswa \\
\cline { 2 - 2 } Sumber: nilai UTS PGMIPA prodi Matematika UAD TA 2012/2013
\end{tabular}

Salah satu upaya yang dapat dilakukan untuk meningkatkan hasil belajar mahasiswa pada mata kuliah kalkulus integral adalah dengan melakukan pembelajaran yang lebih terpusat pada siswa (student oriented) sehingga mahasiswa lebih berperan aktif selama pembelajaran berlangsung melalui metode pembelajaran kooperatif Tipe STAD.

Dalam proses belajar mengajar pemilihan metode pembelajaran merupakan salah satu bagian yang penting untuk dilakukan, agar hasil belajar yang diperoleh dapat optimal. Gulo (2004) dalam Sugihartono dkk (2007:80) mendefinisikan pembelajaran sebagai usaha untuk menciptakan sistem lingkungan yang mengoptimalkan kegiatan belajar. Pendapat lain juga dikemukakan oleh Sudjana (2000) pembelajaran merupakan setiap upaya yang dilakukan dengan sengaja oleh pendidik yang dapat menyebabkan peserta didik melakukan kegiatan belajar (Sugihartono dkk: 2007: 80).

Pembelajaran yang dirancang oleh dosen dapat menggunakan metode pembelajaran kooperatif. Pembelajaran kooperatif adalah model pembelajaran yang mengelompokkan mahasiswa untuk tujuan menciptakan pendekatan pembelajaran yang berefektifitas yang mengintegrasikan ketrampilan sosial yang bermuatan akademik. Menurut Slavin pembelajaran kooperatif adalah suatu model pembelajaran di mana mahasiswa belajar dan bekerjasama dengan kelompok-kelompok kecil secara kolaboratif yang anggotanya terdiri dari 4-6 orang dengan struktur kelompok heterogen. Jadi pada pembelajaran kooperatif mempunyai keuntungan/manfaat adanya kerjasama antar kelompok. Salah satu metode kooperatif adalah metode pembelajaran kooperatif tipe STAD.

STAD merupakan salah satu tipe metode pembelajaran kooperatif yang paling sederhana, dan merupakan model yang paling baik untuk permulaan bagi para guru(dosen) yang baru menggunakan pendekatan kooperatif In STAD, the students teams must master some contens, ussually presented by the teacher, perhaps new vocabulary. Students work in teams to ensure that all members can perform well on an upcoming vocabulary quiz. The STAD process involves teacher presentation, team study, individual quizzes, determination of team scores, and team reward or recognition .

Menurut Agus Suprijono (2011:133) langkah-langkah dalam pembelajaran kooperatif tipe STAD adalah sebagai berikut: (1). Membentuk kelompok yang anggotanya empat orang secara heterogen (campuran menurut prestasi, jenis kelamin, suku dan lain-lain), (2). Guru (dosen) menyajikan pelajaran, (3). Guru (dosen) memberi tugas kepada kelompok untuk dikerjakan oleh anggota-anggota kelompok. Anggotanya yang sudah mengerti dapat menjelaskan pada anggota yang lainnya sampai semua anggota dalam kelompok itu mengerti (4). Guru (dosen) memberi kuis/pertanyaan kepada seluruh siswa (mahasiswa). Pada saat menjawab kuis tidak boleh saling membantu, (5). Memberi evaluasi dan (6). Kesimpulan.

Peran aktif mahasiswa selama proses belajar mengajar mengacu pada 6 indikator yang terdapat pada Direktorat Pembinaan SMA, 2010 yang masing-masing dirinci dalam 4 pernyataan. Adapun indikator-indikator tersebut adalah: (1). Antusias mahasiswa dalam mengikuti pembelajaran, (2) Interaksi mahasiswa dengan dosen, (3) Interaksi antar mahasiswa, (4) Kerjasama kelompok, (5) Aktivitas mahasiswa dalam kelompok, dan (6) Partisipasi mahasiswa dalam menyimpulkan hasil pembahasan. 


\section{Metode Penelitian}

Jenis penelitian yang digunakan adalah penelitian tindakan kelas dengan menggunakan analisis deskriptif kualitatif, karena penelitian ini menggambarkan fenomena-fenomena yang terjadi di lapangan, sehingga data yang diambil berupa kata-kata atau kalimat yang menggambarkan kondisi dan situasi yang ada di lapangan pada saat kegiatan pembelajaran kooperatif tipe STAD dilakukan.

Tempat dan waktu penelitian ini dilaksanakan di PG MIPA Program Studi Pendidikan Matematika UAD semester gasal tahun akademik 2012/2013. Subyek penelitian ini adalah seluruh mahasiswa PGMIPA BI prodi pendidikan matematrika FKIP UAD semester III tahun akademik 2012/2013 sebanyak 20 mahasiswa. Obyek penelitian adalah peningkatan peran aktif mahasiswa dalam mata kuliah kalkulus integral melalui metode pembelajaran kooperatif tipe STAD.

\section{Prosedur Pengumpulan Data}

Prosedur pengumpulan data yang digunakan dalam penelitian ini, adalah: (1) Menggunakan lembar observasi untuk memperoleh data tentang peran aktif mahasiswa, (2) Wawancara dilakukan pada mahasiswa di setiap akhir siklus untuk menanyakan pendapat, saran, tanggapan dan hambatannya selama dilakukan pembelajaran dengan menggunakan model pembelajaran kooperatif tipe STAD, (3) Melakukan tes diagnostik, (4) Catatan lapangan dan (5) Dokumentasi.

\section{Teknik analisis data}

Data hasil observasi diolah dan selanjutnya dikriteriakan atau dikategorikan dengan menggunakan tabel sebagai berikut:

Tabel 2 Kualifikasi Hasil Persentase Skor Peran Aktif Mahasiswa.

\begin{tabular}{cc}
\hline Presentase Peran Aktif Mahasiswa (\%) & Tingkat Peran Aktif Mahasiswa \\
\hline $81-100$ & Sangat Tinggi \\
$61-80$ & Tinggi \\
$41-60$ & Cukup \\
$21-40$ & Kurang \\
$0-20$ & Sangat Kurang \\
\hline Riduwan (2010:15)
\end{tabular}

Data yang diperoleh juga dianalisis secara deskriptif kualitatif yaitu menyajikan data dalam bentuk uraian serta pembahasan berdasarkan hasil penelitian. Teknik kualitatif digunakan untuk menentukan keterlaksanaan penelitian tindakan dan menentukan hambatan- hambatan yang muncul dalam pelaksanaan pembelajaran.

\section{Tahap Pelaksanaan Tindakan}

Pelaksanaan tindakan yang dimaksud adalah melaksanakan proses pembelajaran kalkulus integral dengan menggunakan metode pembelajaran kooperatif tipe STAD pada materi teknik pengintegralan. Pelaksanaan kegiatan pembelajaran setiap tindakan dengan model yang dikembangkan oleh Kemmis \& Taggart (Suharsimi Arikunto, 2007: 16) yang meliputi 4 tahap yang membentuk suatu siklus, yaitu (1) perencanaan tindakan, (2) pelaksanaan tindakan, (3) pengamatan, dan (4) refleksi.

Untuk melihat keberhasilan penelitian yang telah dilakukan digunakan kriteria keberhasilan capaian. Adapun indikator keberhasilan capaian apabila peran aktif mahasiswa mengalami peningkatan ratarata skor peran aktif mahasiswa dari satu siklus ke siklus berikutnya dan telah mencapai kategori baik atau sangat baik (persentase rata-rata skor peran aktif mahasiswa $>60 \%$ ).

\section{Hasil Dan Pembahasan}

Penelitian ini telah dilaksanakan di PG MIPA Program studi Pendidikan Matematika UAD semester III yang mengambil mata kuliah kalkulus integral tahun akademik 2012/2013 mulai bulan Nopember 
sampai dengan Desember 2012, dengan jumlah mahasiswa sebanyak 20 orang, meliputi 7 laki-laki dan 13 perempuan.

Berdasarkan data hasil pengamatan terhadap peran aktif mahasiswa pada siklus I sampai siklus III selama proses pembelajaran kegiatan Penelitian diperoleh deskripsi data pada Tabel 3 sebagai berikut:

Tabel 3 Hasil Analisis Peran Aktif Mahasiswa Siklus I sampai siklus III.

\begin{tabular}{|c|c|c|c|}
\hline Indikator & Siklus I & Siklus II & Siklus III \\
\hline Antusias mahasiswa dalam mengikuti pembelajaran & $83.82 \%$ & $90.79 \%$ & $100.00 \%$ \\
\hline Interaksi mahasiswa dengan dosen & $23.53 \%$ & $51.32 \%$ & $80.56 \%$ \\
\hline Interaksi antar mahasiswa & $50.00 \%$ & $52.63 \%$ & $54.17 \%$ \\
\hline Kerjasama Kelompok & $57.35 \%$ & $78.95 \%$ & $68.06 \%$ \\
\hline Aktivitas mahasiswa dalam kelompok & $35.29 \%$ & $53.95 \%$ & $62.50 \%$ \\
\hline Partisipasi mahasiswa dalam menyimpulkan hasil pembahasan & $41.18 \%$ & $27.63 \%$ & $65.28 \%$ \\
\hline Total & $48.53 \%$ & $59.21 \%$ & $71.76 \%$ \\
\hline
\end{tabular}

Dari Tabel 3 di atas pada siklus I diperoleh persentasi peran aktif mahasiswa sebesar $48.53 \%$ dalam kategori cukup. Berdasakan hasil observasi pada siklus I ini, ada dua indikator dalam kategori kurang yaitu pada indicator interaksi mahasiswa dengan dosen dan aktivitas mahasiswa dalam kelompok. Setelah peneliti melakukan wawancara terhadap 3 orang mahasiswa yang diambil secara acak, mahasiswa tersebut mengatakan bahwa mahasiswa senang dengan metode pembelajaran kooperatif tipe STAD, terkait dengan interaksi dengan dosen, mahasiswa menyatakan masih malu bertanya dengan dosen dan lebih memilih bertanya dengan mahasiswa. Aktifitas dalam kelompok belum dilakukan secara optimal karena masih belum terbiasa dengan belajar secara kelompok.

Pada siklus II setelah peneliti melakukan perbaikan atas masukan dan hasil observasi yang diperoleh di siklus I, diperoleh data peran aktif mahasiswa pada siklus II untuk kategori partisipasi mahasiswa dalam menyimpulkan hasil pembahasan mengalami penurunan dibanding dengan siklus I, hasil pengamatan ini setelah dicek dengan hasil wawancara pada 3 mahasiswa, mahasiswa ternyata tidak berani mengemukakan pendapatnya seperti pada siklus I karena takut salah kalau berpendapat.

Pada siklus III peneliti melakukan perbaikan perbaikan berdasar pada hasil refleksi siklus II, yaitu peneliti memotivasi mahasiswa agar berperan aktif selama proses belajar mengajar berlangsung dan jangan takut untuk berpendapat. Dari siklus III peran aktif mahasiswa mencapai $71.76 \%$ dan telah mencapai kategori baik. Pada masing-masing indikator peran aktif mahasiswa pada siklus III dalam kategori baik atau sangat baik, dan hanya ada satu indikator dalam kategori cukup yaitu interaksi antar mahasiswa.

Jumlah mahasiswa yang memiliki peran aktif belajar selama proses belajar mengajar untuk masingmasing siklus dapat dilihat pada Tabel 4 berikut:

Tabel 4 Kriteria Kualifikasi Peran Aktif Mahasiswa Siklus I, II dan III.

\begin{tabular}{clccc}
\hline \multirow{2}{*}{ No } & \multirow{2}{*}{ Kriteria } & \multicolumn{3}{c}{ Jumlah Mahasiswa } \\
\cline { 2 - 4 } & & Siklus I & Siklus II & Siklus III \\
\hline 1 & Sangat tinggi & 1 & 1 & 2 \\
2 & Tinggi & 2 & 7 & 12 \\
3 & Cukup & 9 & 11 & 6 \\
4 & Kurang & 4 & 0 & 0 \\
5 & Sangat kurang & 0 & 0 & 0 \\
\hline & Jumlah & 17 & 19 & 20 \\
\hline
\end{tabular}

Pada siklus I ini, ada 4 mahasiswa yang kurang berperan aktif selama proses belajar mengajar dan hanya ada satu mahasiswa yang memiliki peran aktif belajar sangat tinggi. Pada siklus II dan III semua mahasiswa sudah berperan aktif. Jika dilihat dari tabel di atas, telah terjadi peningkatan peran aktif mahasiswa dari siklus ke siklus berikutnya. Hal ini menunjukkan bahwa metode pembelajaran kooperatif tipe STAD dapat meningkatkan peran aktif mahasiswa. 
Apabila dilihat dari hasil tes diagnostik yang dilakukan pada siklus I, siklus II dan siklus III nilai rata-rata yang diperoleh mahasiswa mengalami peningkatan, seperti yang ditunjukkan pada tabel berikut:

Tabel 5 Hasil Tes Diagnostik.

\begin{tabular}{lccc}
\hline Nilai Mahasiswa & Siklus I & Siklus II & Siklus III \\
\hline Nilai tertinggi & 90 & 100 & 100 \\
Nilai terendah & 30 & 35 & 60 \\
Nilai rata-rata & 61.11 & 66.84 & 78.64 \\
Presentase Nilai A,B (N66) & $47.06 \%$ & $57.89 \%$ & $55 \%$ \\
Presentase Nilai C (55N <66) & $23.53 \%$ & $21.03 \%$ & $45 \%$ \\
Presentase Nilai D,E (N 54) & $29.41 \%$ & $21.03 \%$ & $0 \%$ \\
\hline
\end{tabular}

Dari data-data yang diperoleh di atas baik dari hasil pengamatan, wawancara dan tes diagnostik, dapat dikatakan bahwa telah terjadi peningkatan peran aktif mahasiswa dengan menggunakan metode pembelajaran kooperatif tipe STAD untuk mata kuliah kalkulus integral dengan materi teknik pengintegralan. Antusiasme mahasiswa tinggi dalam mengikuti perkuliahan, interaksi mahasiswa dengan dosen meningkat dari yang awalnya malu dan takut bertanya pada dosen menjadi lebih berani bertanya, kegiatan diskusi kelompok dan diskusi kelas terlihat lebih aktif, mahasiswa sudah semakin berani mengemukakan pendapatnya dan tidak takut salah. Peningkatan peran aktif mahasiswa ini juga disertai dengan peningkatan hasil belajar mahasiswa.

\section{Kesimpulan Dan Saran}

\section{Kesimpulan}

Berdasarkan hasil penelitian melalui pembelajaran dengan menggunakan metode pembelajaran kooperatif tipe STAD dapat ditarik kesimpulan sebagai berikut:

1. Adanya peningkatan peran aktif mahasiswa. Hal ini terbutki dari hasil pada siklus I peran aktif mahasiswa sebesar $48.53 \%$,pada siklus II meningkat menjadi $59.21 \%$ dan pada siklus III menjadi $71.76 \%$.

2. Adanya peningkatan hasil belajar kalkulus integral mahasiswa. Hal ini terbukti dari hasil tes diagnostik mahasiswa pada tiap siklus yang mengalami peningkatan, yaitu nilai rata-rata pada siklus I sebesar 61.11, pada siklus II meningkat menjadi 66.84 dan pada siklus III meningkat sebesar 78.64 .

\section{Saran}

Berdasarkan penelitian yang telah dilakukan ada beberapa saran yang dapat peneliti sampaikan, yaitu:

1. Bagi mahasiswa PGMIPA Program studi pendidikan matematika UAD, agar memiliki rasa percaya diri bahwa dalam mengikuti kegiatan perkuliahan perlu adanya peran aktif dari diri sendiri agar memperoleh prestasi belajar yang optimal.

2. Bagi dosen PGMIPA Program studi pendidikan matematika UAD, agar lebih mengaktifkan mahasiswa selama kegiatan belajar mengajar. Adanya pemilihan metode pembelajaran yang tepat akan dapat meningkatkan peran aktif mahasiswa.

3. Bagi peneliti lain, agar mau mencoba menerapkan metode pembelajaran kooperatif tipe STAD untuk materi-materi pelajaran (kuliah) yang lain. 


\section{Referensi}

[1] Agus Suprijono. 2011. Cooperative Learning Teori dan Aplikasi PAIKEM. Yogyakarta: Pustaka Pelajar.

[2] Direktorat Pembinaan SMA, 2010, Petunjuk Teknis Penyusunan Perangkat Penilaian Efektif di Sekolah Menengah Atas. Jakarta: DIRJEN MENDIKDASMEN, KEMENDIKNAS.

[3] Riduwan. 2010. Skala Pengukuran Variabel-Variabel Penelitian. Bandung: Alfabeta.

[4] Robert E Slavin. 2010. Cooperative Learning Teori, Riset dan Praktik. Bandung: Nusa Media.

[5] Sugihartono dkk. 2007. Psikologi Pendidikan. Yogyakarta: UNY Press.

[6] Suharsimi Arikunto. 2007. Penelitian Tindakan Kelas.Jakarta: PT Bumi Aksara. 